\title{
Protein Kinase C-delta Stimulates Haptoglobin Secretion
}

\author{
Mi-Kyung Oh${ }^{1}$, Seon-Joo Park', Nam-Hoon Kim ${ }^{1}$ and In-Sook Kim ${ }^{1, *}$ \\ ${ }^{1}$ Department of Natural Sciences, Chemistry Section, College of Medicine, The Catholic University of Korea, Seoul 137-701, Korea
}

Received 14 June 2006, Accepted 12 October 2006

\begin{abstract}
Haptoglobin (Hp) is a glycoprotein that is produced by hepatic cells and secreted into the circulation. While studying the physiologic functions of $\mathrm{Hp}$, we found that $\mathrm{Hp}$ synthesized in THP-1 monocytic cells was largely retained within cells, although $\mathrm{Hp}$ is considered a secretory protein. To investigate the molecular mechanism on Hp secretion in THP-1 cells, in the present study, we examined the effect of protein kinase $\mathrm{C}$ (PKC) on Hp secretion. When several inhibitors of PKC isoforms were tested, only Rottlerin, a specific inhibitor of PKC- $\delta$, completely blocked Hp secretion from cells to culture medium. To confirm the role of PKC- $\delta$ in Hp secretion, Hp-overexpressing COS7 cells were transiently transfected with a wild-type or a dominantnegative mutant of the PKC- $\delta$ gene. Mutant PKC- $\delta$ significantly inhibited Hp secretion, whereas the wild-type gene slightly increased $\mathrm{Hp}$ secretion. These results demonstrate that the $\mathrm{PKC}-\delta$ signal is involved in $\mathrm{Hp}$ secretion.
\end{abstract}

Keywords: Haptoglobin, Protein kinase C- $\delta$, Secretion, Rottlerin, THP-1 cells

\section{Introduction}

Haptoglobin ( $\mathrm{Hp}$ ) is a major acute-phase plasma protein that is synthesized in the liver and secreted into the circulation. The plasma concentrations of $\mathrm{Hp}$ increase 2-4-fold during inflammation, infection, trauma or malignancy (Baumann and Gauldie, 1994). Because of its strong hemoglobin (Hb)-

\footnotetext{
Abbreviations: Hp, haptoglobin; PMA, phorbol-12-myristate 13acetate; PKC, protein kinase $\mathrm{C}$; $\mathrm{Hb}$, hemoglobin; proHp, Hp precursor; ATRA, all-trans retinoic acid; GFP, green fluorescence protein; $\mathrm{C} / \mathrm{EBP}, \mathrm{CCAAT} / \mathrm{enhancer}$-binding protein
}

*To whom correspondence should be addressed.

Tel: 82-2-590-1269; Fax: 82-2-592-7068

E-mail: ikim@catholic.ac.kr binding activity, $\mathrm{Hp}$ can minimize $\mathrm{Hb}$-stimulated lipid peroxidation and protect DNA and tissues against oxidative damage during hemolytic injury (Kim, 1996; Lim et al., 2000; Yang et al., 2003). Thus, physiologically, Hp has been considered to be an antioxidant. Several reports have suggested other roles of $\mathrm{Hp}$, and it may also function as an angiogenic factor, a cell migration factor, and as an immunomodulator ( $\mathrm{Oh}$ et al., 1990; Cid et al., 1993; Berkova et al., 1999; de Klejin et al., 2002).

$\mathrm{Hp}$ is biosynthesized initially as a single precursor polypeptide (preproHp), which contains an amino-terminal signal sequence followed directly by an $\alpha$-subunit region and also has a $\beta$ subunit region at the carboxyl-terminal. Cotranslational processing of preproHp results in the removal of the signal peptide and core glycosylation of the $\beta$-subunit region to yield proHp. Thereafter, proHp forms a dimer using interchain and intrachain disulfide bonds, which is proteolytically cleaved to give separated $\alpha$ - and $\beta$-chains. The resultant $\alpha_{2} \beta_{2}$ heterotetramer, which is linked by disulfide bridges, is mature form of $\mathrm{Hp}$. Both mature $\mathrm{Hp}$ and proHp undergo terminal glycosylation and are then secreted into the circulation (Hanley et al., 1983; Hanley and Heath, 1985).

The liver is regarded as the main site of Hp synthesis. Hp expression in response to inflammation has been extensively studied in hepatoma cells, and particular attention has been focused on transcriptional activation and processing during biosynthesis (Hanley et al., 1983; Hanley and Heath, 1985; Bowman, 1993). Recent studies, however, have demonstrated the extrahepatic expression of $\mathrm{Hp}$ in adipose tissue, lung, intestinal epithelial cells, and ischemic astrocytes (Friedrichs et al., 1995; Desilets et al., 2000; Lee et al., 2002; Yang et al., 2002). These findings suggest that $\mathrm{Hp}$ is generated locally by various stimulants and may have new specific local biological functions.

In previous work, we observed $\mathrm{Hp}$ gene expression in THP-1 monocytic cells, in which its expression was induced by all-trans retinoic acid (ATRA) (Kim et al., 2001; Lee et al., 2002). Notably, most Hp produced in THP-1 cells was not released, although $\mathrm{Hp}$ is regarded to be a secretory protein. Because it was reported that secretion of $\mathrm{C} 3$ protein is 
regulated by the PKC-dependent pathway in monocytes, we investigated the relationship between Hp secretion and protein kinase $\mathrm{C}$ (PKC) activation. Our findings demonstrate for the first time that PKC- $\delta$ activation is involved in $\mathrm{Hp}$ secretion.

\section{Materials and Methods}

Cell culture and treatment. THP- 1 and COS7 cells were maintained in RPMI 1640 medium and Dulbecco's Minimal Eagle's Medium (DMEM) (Gibco Life Technology) supplemented with 10\% fetal bovine serum (FBS; Gibco Life Technology), respectively. To examine the effects of PKC on Hp secretion, cells were exposed to various inhibitors of PKC isoforms (Gö 6976, Calbiochem; Rottlerin, Calbiochem; LY 333531, Alexis Corp.) for $24 \mathrm{~h}$.

Cell transfection. Human Hp2 cDNA (Kim et al., 2001) was ligated between the EcoRI and $X h o$ I sites of MPG retroviral vector containing a gene for green fluorescence protein (GFP) to produce the recombinant plasmid MPG-Hp. Phoenix-Ampho virus packaging cells $\left(7.5 \times 10^{6}\right.$ cells $)$ were seeded in a $10 \mathrm{~cm}$ flask and incubated for $24 \mathrm{~h}$. The medium was then renewed with fresh DMEM, and 3$4 \mathrm{~h}$ later, a mixture of $10 \mu \mathrm{g}$ of MPG-Hp plasmid DNA and FuGene6 reagent (Roche) was added. After transfection for $48 \mathrm{~h}$, $60 \mathrm{~h}$ or $72 \mathrm{~h}$, virus-containing supernatants were collected and used to infect THP-1 cells, and $24 \mathrm{~h}$ later, GFP-positive cells were separated using a flow cytometric cell sorter (BD Biosciences).

To prepare Hp-overexpressing COS7 cells, Hp2 cDNA was cloned into pCR3.1 vector (Invitrogen) and cells were transfected using FuGene6 reagent, according to the manufacturer's protocol. To select stable transfectants, the cells were exposed to $1 \mathrm{mg} / \mathrm{ml}$ of G418 (Invitrogen). Hp-overexpressing COS7 cells were also transfected with PKC- $\delta$ gene using Lipofectamine 2000 (Invitrogen). Briefly, $4 \times 10^{5}$ cells/well were plated in a six-well plate and treated with a mixture of Lipofectamine 2000 and PKC- $\delta$ DNA (wild-type or dominant negative mutant) subcloned in pcDNA3 vector. After $6 \mathrm{~h}$ of treatment, the culture medium renewed with fresh DMEM containing $10 \%$ FBS, and transfected cells were further incubated for $42 \mathrm{~h}$.

Western blot analysis. Cells were lysed in RIPA buffer $(50 \mathrm{mM}$ Tris- $\mathrm{HCl}, \mathrm{pH} 7.5,150 \mathrm{mM} \mathrm{NaCl}, 1 \%$ Nonidet P-40, 0.5\% sodium deoxycholate, $0.1 \%$ sodium dodecyl sulfate (SDS), $1 \mathrm{mM}$ phenylmethylsulfonyl fluoride) for $30 \mathrm{~min}$ on ice. Cell lysates were then denatured, separated in 12\% SDS-polyacrylamide gel, and transferred to nitrocellulose membranes. The membranes were then blocked for $1 \mathrm{~h}$ at room temperature in PBS containing 5\% skim milk, and blots were incubated overnight at $4^{\circ} \mathrm{C}$ with anti-Hp antibody (Sigma) or anti-HA antibody (Santa Cruz Biotechnology). After washing, membranes were incubated with peroxidase-conjugated secondary anti-rabbit IgG (Sigma). Proteins analyzed were visualized using an enhanced chemiluminescence detection kit (Amersham Pharmacia Biotech).

\section{Results and Discussion}

Increase of Hp secretion by PMA. In a previous study, we
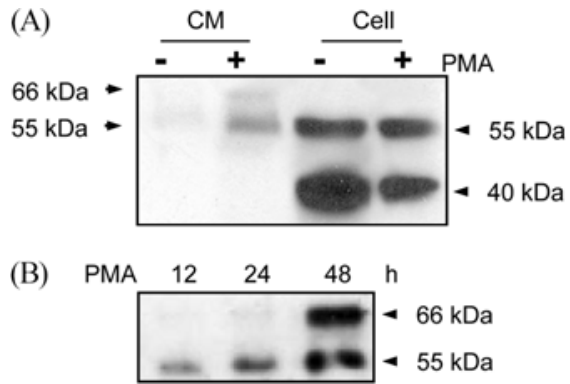

Fig. 1. PMA-induced stimulation of Hp secretion by THP-1 cells. THP-1 monocytic cells were transfected with the human Hp2 gene. Hp-overexpressing cells were seeded at a density of $1 \times 10^{6} / \mathrm{ml}$ and incubated in medium containing $100 \mathrm{nM}$ PMA overnight (A) or for the indicated times (B). Cells were then washed twice with PBS and further cultured for $24 \mathrm{~h}$ in serumfree RPMI 1640 medium. $10 \mu \mathrm{l}$ of cell culture medium (CM) and $50 \mu \mathrm{g}$ of cellular protein (Cell) were analyzed by Western blotting using anti-human $\mathrm{Hp}$ antibody. The detected bands correspond to the $\beta$-chain of Hp. $\beta$-Chains were larger in $\mathrm{CM}$ than in cells, presumably due to different glycosylation levels.

showed that ATRA-stimulated monocytic cells synthesized Hp (Kim et al., 2001). Interestingly, most of the Hp synthesized in monocytic cells was not released, even though $\mathrm{Hp}$ is regarded as a secretory protein. To invest the mechanism underlying $\mathrm{Hp}$ secretion, we first examined whether PMA could facilitate Hp secretion. To prepare Hp-overexpressing monocytes, human Hp gene was introduced into THP-1 cells. These cells produced Hp efficiently, however, little Hp was detected in cell culture medium (Fig. 1A). However, when the cells were stimulated with $100 \mathrm{nM}$ PMA, Hp was released from cells to the culture medium (Fig. 1A), and the amount of secreted Hp gradually increased in a time-dependent manner for $48 \mathrm{~h}$ after PMA treatment (Fig. 1B). To identify whether other nonhepatic cells are also defective in terms of $\mathrm{Hp}$ secretion, Hp-overexpressing COS7 monkey kidney cells, Hp-overexpressing A172 human glioma cells, and Hpoverexpressing A549 human lung cells were established by transfection with the $\mathrm{Hp}$ gene. Western blot analysis easily detected $\mathrm{Hp}$ in all culture media of these cell types (data not shown). Therefore, it is likely that Hp retention within cells is not a characteristic of nonhepatic cells, but that it is specific to THP-1 monocytes.

The $\mathrm{Hp} \beta$-chain is approximately $39 \mathrm{kDa}$ in length. Theilgaard-Mönch et al. (2006) reported that neutrophils contained a highly glycosylated $\mathrm{Hp}$ ( $\beta$-chain $45-65 \mathrm{kDa}$ ), which is synthesized in neutrophil precursor cells and stored in specific granules. In the present study, THP-1 monocytic cells contained two $\mathrm{Hp} \beta$-chain types of $40 \mathrm{kDa}$ and $55 \mathrm{kDa}$ (Fig. 1A); it is likely that the $55 \mathrm{kDa}$-band corresponds to a more glycosylated form. The glycosylation of $\mathrm{Hp}$ occurs during cotranslational processing (Hanley and Heath, 1985), and fully glycosylated $\mathrm{Hp}$ is secreted, and therefore, the $40 \mathrm{kDa}-$ band was not detected in culture medium (Fig. 1A). In culture 


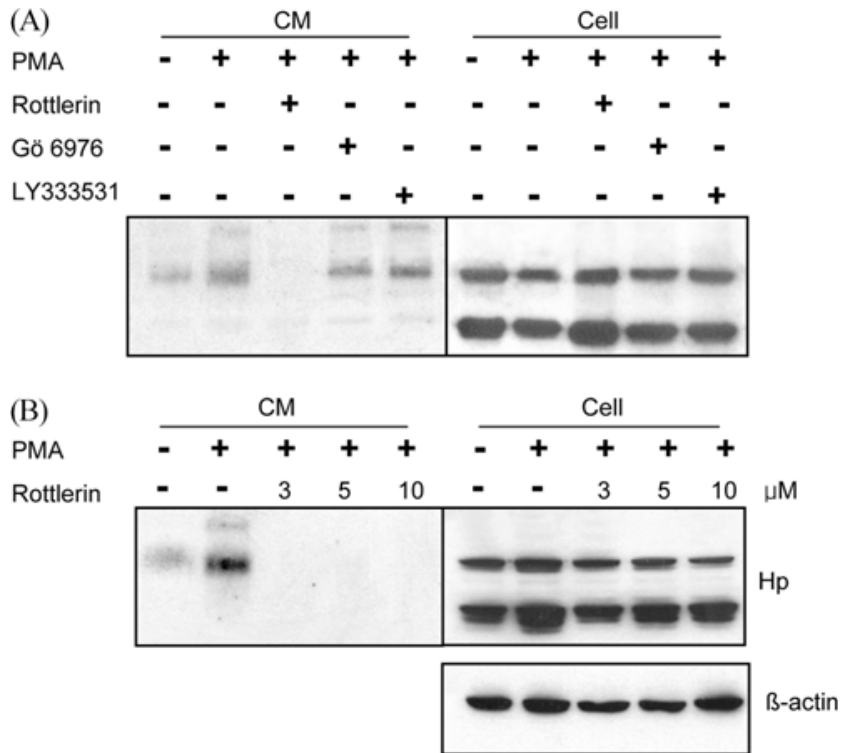

Fig. 2. The effect of $\mathrm{PKC}$ inhibitors on PMA-stimulated $\mathrm{Hp}$ release. Hp-overexpressing THP-1 cells were preincubated with PKC inhibitors for $1 \mathrm{~h}$ before PMA treatment. The inhibitors used were Rottlerin $(5 \mu \mathrm{M})$, Gö $6976(10 \mathrm{nM})$, or LY 333531 $(500 \mathrm{nM})$. After preincubation, PMA $(100 \mathrm{nM})$ was added to cells, which were then further incubated for $24 \mathrm{~h}$. The $\mathrm{Hp}$ protein in cell culture media (CM) and within cells was detected by Western blotting using anti-Hp antibody. Note that only Rottlerin inhibited Hp release (A), and that at more than $3 \mu \mathrm{M}$ Rottlerin completely blocked PMA-stimulated Hp secretion (B).

medium, another $66 \mathrm{kDa}$-band after PMA treatment (Figs. 1A and B). This appeared to be a further modified form of $\mathrm{Hp} \beta$ chain resulted from activation by PMA. However, further study is required to determine whether it is attributable to heavy glycosylation.

The effect of PKC on Hp secretion. PMA is known to be a PKC activator. The ability of PKC to mediate Hp secretion was therefore evaluated using various inhibitors of PKC isoforms. Hp gene-transfected THP-1 cells were treated with Rottlerin (an inhibitor of PKC- $\delta$ and PKC- $\theta$ ), Gö 6976 (an inhibitor of PKC- $\alpha$ ) or LY 333531 (an inhibitor of PKC- $\beta$ ), and incubated for $1 \mathrm{~h}$. After preincubation for $1 \mathrm{~h}$, PMA was added to cell cultures and cells were further incubated for $24 \mathrm{~h}$. When Hp levels in cell culture media were assayed, it was found that Rottlerin significantly blocked Hp secretion, whereas Gö 6976 and LY 333531 did not affect this process (Fig. 2A). In fact, Rottlerin at more than $3 \mu \mathrm{M}$ completely inhibited PMA-stimulated Hp secretion (Fig. 2B).

When Hp was synthesized in COS7 kidney epithelial cells, it was found to be well secreted by cells without PMA treatment, probably due to intrinsic PKC activity. To identify whether PKC activity is also associated with Hp secretion by COS7 cells, Hp-expressing COS7 cells were treated with Rottlerin, Gö 6976, or LY 333531 and incubated for $24 \mathrm{~h}$. As
(A)

Rottlerin

Gö 6976

LY333531

$72 \mathrm{kDa}$

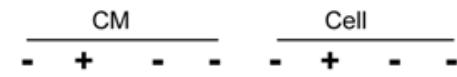

(B)

Rottlerin
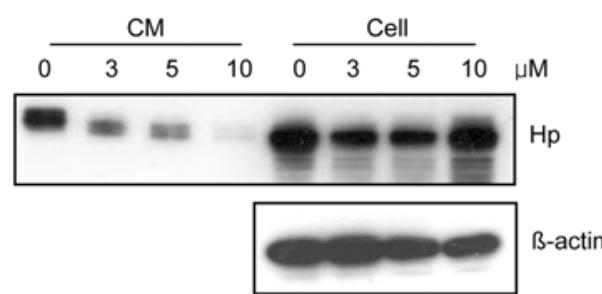

Fig. 3. The inhibitory effect of Rottlerin on $\mathrm{Hp}$ release by COS7 cells. Hp-overexpressing COS7 cells were cultured for $24 \mathrm{~h}$ in the presence of PKC inhibitors. Cell culture medium (CM) and cell lysates were examined for $\mathrm{Hp}$. Rottlerin significantly blocked Hp secretion, whereas Gö 6976 and LY 333531 did not (A), and this inhibitory effect of Rottlerin was concentrationdependent up to $10 \mu \mathrm{M}(\mathrm{B})$.

shown in Fig. 3A, whereas Rottlerin inhibited Hp secretion, Gö 6976 and LY 333531 did not. Moreover, the inhibitory effect of Rottlerin was concentration-dependent up to $10 \mu \mathrm{M}$ (Fig. 3B). These results suggest that PKC- $\delta$ activity, stimulated by PMA or by intrinsic activity, contributes to Hp secretion.

$\mathrm{Hp}$ is initially synthesized as an $\alpha \beta$-precursor form, which is proteolytically cleaved in the endoplasmic reticulum. As a result, $\alpha \beta$-precursor is separated into $\alpha$ - and $\beta$-chains (Hanley and Heath, 1985). Moreover, complement C1r-like protein, which is synthesized in hepatoma cells, was recently identified as a specific protease for this cleavage (Wicher and Fries, 2004). The size of Hp secreted from COS7 kidney cells was $72 \mathrm{kDa}$ (Fig. 3), whereas the $\mathrm{Hp} \beta$ - and $\alpha_{2}$-chains secreted by HepG2 hepatoma cells were $47 \mathrm{kDa}$ and $22 \mathrm{kDa}$, respectively (data not shown). Thus, it is likely that the Hp in COS7 cells is a precursor form consisting of an unseparated $\alpha \beta$-chain, because of the absence of a specific protease capable of cleaving $\mathrm{Hp}$ precursor. The findings of other studies support this explanation, e.g., it was found that the $\alpha \beta$-precursor form was present in Hp-overexpressing COS-1 kidney cells (Hanley and Heath, 1985).

Involvement of $\mathrm{PKC}-\delta$ activation in $\mathrm{Hp}$ release. To confirm whether PKC- $\delta$ acts directly to increase Hp secretion, Hpoverexpressing COS7 cells were transiently transfected with wild type or dominant negative mutant constructs of the PKC$\delta$ gene. The wild type and mutant gene constructs contained the full-length open reading frame or a point mutation (K376R) in the ATP binding site, respectively (Soh et al., 1999). Cells transfected with wild $\mathrm{PKC}-\delta$ released more $\mathrm{Hp}$ than those transfected with vector. In contrast, Hp release was partially inhibited by mutant PKC- $\delta$ (Fig. 4). Taken together, these data 
(A)

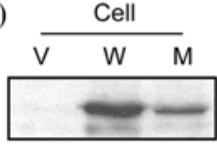

HA
(B)

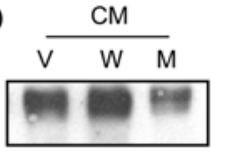

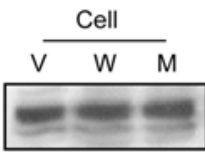

$\mathrm{Hp}$
Fig. 4. Involvement of PKC- $\delta$ activity in Hp secretion. Wild-type and dominant negative mutant $\mathrm{PKC}-\delta$ genes were introduced into Hp-overproducing COS7 cells. After $48 \mathrm{~h}$ of transfection, PKC- $\delta$ expression levels (A) and Hp release (B) were analyzed by Western blotting. V, W and $\mathrm{M}$ indicate transfection by empty control vector DNA (pcDNA3), wild-type PKC- $\delta$ DNA, and mutant PKC- $\delta$ DNA, respectively. Note that pcDNA3 vector did not contain the histidine-tag, but that PKC- $\delta$ DNAs were tagged with oligohistidines. Similar results were obtained from three independent experiments.

indicate that PKC- $\delta$ might be involved in a signaling process leading to $\mathrm{Hp}$ secretion.

In a previous report (Lee et al., 2002), we showed that Hp is synthesized via the transcriptional activity of CCAAT enhancer binding protein alpha $(\mathrm{C} / \mathrm{EBP} \alpha)$ in a THP-1 monocytic cell line stimulated by ATRA, a well known differentiationinducing agent. In addition, we observed $\mathrm{Hp}$ generation during the ATRA-induced granulocytic differentiation of HL60 promyelocytic leukemia cells, although the Hp produced remained mainly within cells (data not shown). During the preparation of this paper, Theilgaard-Mönch et al. (2006) reported that $\mathrm{Hp}$ is synthesized via the transcriptional activity of $\mathrm{C} / \mathrm{EBP} \varepsilon$ in neutrophil precursors during granulocytic differentiation, and that this $\mathrm{Hp}$ is then stored in secretory vesicles as a neutrophil granule protein. Moreover, when neutrophils were stimulated by PMA, stored $\mathrm{Hp}$ was found to be released into medium (Theilgaard-Mönch et al., 2006). Wagner et al. (1996) also detected Hp within peripheral blood leukocytes, especially granulocytes and monocytes, and this Hp was exocytosed following granulocyte activation by Candida albicans. Taken together, our findings and those of others suggest that Hp produced in hematic cells is retained within such cells and is finally secreted at specific inflammatory sites when cells are activated by stimulants that transduce a PKC- $\delta$ signal. Goodnight et al. (1995) previously addressed the localization of PKCs in NIH 3T3 fibroblasts overexpressing eight PKC isozymes (PKC- $\alpha,-\beta \mathrm{I},-\beta I,-\gamma,-\delta,-\varepsilon,-\zeta$ and $-\eta)$. Of these isoforms, PKC- $\delta$ and $-\eta$ were found to be concentrated in the Golgi apparatus (Goodnight et al., 1995). These findings suggest that PKC- $\delta$ plays an important role in the transport of secretory proteins, and support the argument present in this paper.

Summarizing, the Hp secretion process appears to be strongly dependent on PKC activation, especially on the activation of PKC- $\delta$. Moreover, the present study provides first evidence that PKC- $\delta$ participates in Hp secretion.

Acknowledgments This work was supported by a Korean Research Foundation Grant funded by the Korean Government
(MOEHRD) (KRF-2003-041-E00044). We thank Dr. Il-Hoan Oh (The Catholic University of Korea) for donating MPG retroviral vector containing the GFP gene and Phoenix-Ampho virus packaging cells, and we thank Dr. Jeong-Hoon Kang (The Catholic University of Korea) for the PKC- $\delta$ constructs.

\section{References}

Baumann, H. and Gauldie, J. (1994) The acute phase response. Immunol. Today 15, 74-80.

Berkova, N., Gilbert, C., Goupil, S., Yan, J., Korobko, V. and Naccache, P. H. (1999) TNF-induced haptoglobin release from human neutrophils: pivotal role of the TNF p55 receptor. $J$. Immunol. 162, 6226-6232.

Cid, M. C., Grant, D. S., Hoffman, G. G., Auerbach, R., Fauci, A. S. and Kleinman, H. K. (1993) Identification of haptoglobin as an angiogenic factor in sera from patients with systemic vasculitis. J. Clin. Invest. 91, 977-985.

Desilets, A., Gheorghiu, I., Yu, S. J., Seidman, E. G. and Asselin, C. (2000) Inhibition by deacetylase inhibitors of IL-1dependent induction of haptoglobin involves CCAAT/enhancerbinding protein isoforms in intestinal epithelial cells. Biochem. Biophys. Res. Commun. 276, 673-679.

Drouin, S. M., Kiley, S. C., Carlino, J. A. and Scott, R. B. (1998) Transforming growth factor- $\beta 2$ regulates $\mathrm{C} 3$ secretion in monocytes through a protein kinase C-dependent pathway. Mol. Immunol. 35, 1-11.

Friedrichs, W. E., Navarijo-Ashbaugh, A. L., Bowman, B. H. and Yang, F. (1995) Expression and inflammatory regulation of haptoglobin gene in adipocytes. Biochem. Biophys. Res. Commun. 209, 250-256.

Goodnight, J. A., Mischak, H., kolch, W. and Mushinski, J. F. (1995) Immunocytochemical localization of eight protein kinase C isozymes overexpressed in NIH 3T3 fibroblasts. J. Biol. Chem. 270, 9991-10001.

Hanley, J. M., Haugen, T. H. and Heath, E. C. (1983) Biosynthesis and processing of rat haptoglobin. J. Biol. Chem. 258, 78587869.

Hanley, J. M. and Heath, E. C. (1985) A novel proteolytic activity in serum processes rat prohaptoglobin. Arch. Biochem. Biophys. 239, 404-419.

Kim, I. S. (1996) Inhibition of hemoglobin-induced low density lipoprotein oxidation by haptoglobin. Exp. Mol. Med. 28, 8994.

Kim, I. S., Lee, I. H., Lee, J. H. and Lee, S. Y. (2001) Induction of haptoglobin by all-trans retinoic acid in THP-1 human monocytic cell line. Biochem. Biophys. Res. Commun. 284, 738-742.

de Klejin, D. P., Smeets, M. B., Kemmeren, P. P., Lim, S. K., Van Middlaar, B. J., Velema, E., Schoneveld, A., Pasterkamp, G. and Borst, C. (2002) Acute-phase protein haptoglobin is a cell migration factor involved in arterial restructuring. FASEB J. 16, 1123-1125.

Lee, I. H., Lee, J. H., Lee, M. J., Lee, S. Y. and Kim, I. S. (2002) Involvement of CCAAT/enhancer-binding protein $\alpha$ in haptoglobin gene expression by all-trans-retinoic acid. Biochem. Biophys. Res. Commun. 294, 956-961.

Lee, M. Y., Kim, S. Y., Choi, J. S., Lee, I. H., Choi, Y. S., Jin, J. 
Y., Park, S. J., Sung, K. W., Chun, M. H. and Kim, I. S. (2002) Upregulation of haptoglobin in reactive astrocytes after transient forebrain ischemia in rats. J. Cereb. Blood Flow Metab. 22,1176-1180.

Lim, Y. K., Jenner, A., Ali, A. B., Wang, Y., Hsu, S. I. H., Chong, S. M., Baumman, H., Halliwell, B. and Lim, S. K. (2000) Haptoglobin reduces renal oxidative DNA and tissue damage during phenylhydrazine-induced hemolysis. Kidney Int. 58, 1033-1044.

Oh, S. K., Pavlotsky, N. and Tauber, A. I. (1990) Specific binding of haptoglobin to human neutrophils and its functional consequences. J. Leukocyte Biol. 47, 142-148.

Soh, J. W., Lee, E. H., Prywes, R. and Weinstein, I. B. (1999) Novel role of specific isoforms of protein kinase $\mathrm{C}$ in activation of the c-fos serum response element. Mol. Cell. Biol. 19, 1313-1324.

Theilgaard-Mönch, K., Jacobsen, L. C., Nielsen, M. J., Rasmussen, T., Udby, L., Gharib, M., Arkwright, P. D., Gombart, A. F., Calafat, J., Moestrup, S. K., Porse, B. T. and Borregaard, N.
(2006) Haptoglobin is synthesized during granulocytic differentiation, stored in specific granules, and relesed by neutrophils in response to activation. Blood 108, 353-361.

Wanger, L., Gessl, A., Parzer, S. B., Base, W., Waldhausl, W. and Pasternack, M. S. (1996) Haptoglobin phenotyping by newly developed monoclonal antibodies. Demonstration of haptoglobin uptake into peripheral blood neutrophils and monocytes. $J$. Immunol. 156, 989-1996.

Wicher, K. B. and Fries, E. (2004) Prohaptoglobin is proteolytically cleaved in the endoplasmic reticulum by the complement $\mathrm{C} 1 \mathrm{r}-$ like protein. Proc. Natl. Acad. Sci. USA 101, 4390-14395.

Yang, F., Ghio, A. J., Herbert, D. C., Weaker, F. J., Water, C. A. and Coalson, J. J. (2002) Pulmonary expression of the human haptoglobin gene. Am. J. Respir. Cell Mol. Biol. 23, 277-282.

Yang, F., Haile, D. J., Berger, F. G., Herbert, D. C., Van Beveren, E. and Ghio, A. J. (2003) Haptoglobin reduces lung injury associated with exposure to blood. Am. J. Physiol. Lung Cell Mol. Physiol. 284, 402-409. 